\title{
Meteorological reports in the Perspective Automated Artillery Fire Support Control System
}

\author{
Martin Blaha \\ Department of Fire Support Control \\ University of Defence \\ Brno, Czech Republic \\ martin.blaha@unob.cz
}

\author{
Ladislav Potužák \\ Department of Fire Support Control \\ University of Defence \\ Brno, Czech Republic \\ mar.blaha@email.cz
}

Received: June 15, 2019. Revised: July 2, 2021. Accepted: October 6, 2021. Published: November 26, 2021.

\begin{abstract}
The Czech Republic, as a member of international organizations (NATO, EU, UNO), with respect to current global security environment, employs the units of the army both at its own state territory and outside the Czech Republic in multinational forces operations. The article focuses on preparation of meteorological reports of future Automated Command, Control, and Information system (C2I) in conditions of the Army of the Czech Republic. The issue of automated command, control, and information systems is of high importance in the solving of asymmetrical operations tasks today and in the upcoming future. Define the basic resources for creation of meteorological reports of NATO standards in Network Enabled Capabilities (NEC) conditions. The authors define group of meteorological report for designing a new and by the Army of the Czech Republic required sophisticated Automated Fire Support Control System of Artillery meeting NATO standards in Network Enabled Capabilities (NEC) conditions. The article represents section of a huge defensive research project of Ministry of Defence of the Czech Republic and the Army of the Czech Republic solved by leading scientists of the University of Defence in Brno.
\end{abstract}

Keywords-Meteorological report, Artillery units, fire support, automated command and control system.

\section{INTRODUCTION}

$\mathrm{M}$ ETEOROLOGICAL conditions affect mainly the firing and thus the effectiveness of artillery fire. For this reason, the identification and interpretation of current weather conditions is prerequisite for fulfilling the tasks of artillery to support task force. Determination of meteorological conditions belongs to the artillery preparation. The content of artillery preparation is a complex sounding of the atmosphere and ground meteorological measuring, preparation of meteorological reports and their delivery to users, tracking cloud, barometric trend and temperature of land and warning units on dangerous phenomena weather. Meteorological artillery preparation provides meteorological squad of Artillery Brigade and mortar batteries.
Artillery of Czech Army uses the meteorological report

- meteorological report METEOSTŘEDNÍ(METEO-11);

- approximate meteorological report METEOSTŘEDNÍPŘIBLIŽNÁ;

- METB - Standard Ballistic Meteorological report (STANAG 4061);

- METCM - Standard Artillery Computer Meteorological report (STANAG 4082).

The content of the papers is to clarify the content and and processing of meteorological reports for the needs of Artillery of Czech Army.

\section{METEOROLOGICAL REPORT METEOSTŘEDNÍ}

Meteorological report METEOSTŘEDNÍ (METEO-11) is used to prepare elements for fire control in the event of fire in an alternative manner. It broadcasts in the specified intervals in radio security networks and all users intercept it. The validity of steady weather is 3 hours in $10 \mathrm{~km}$ from the meteorological station and 2 hours in $35 \mathrm{~km}$ from the meteorological station.

\section{A. The importance of character message}

Scheme of report:

METEO-11 ČČ - DDHHM - VVVV - BBBToTo - 02PP TTSSRR - 04PP - TTSSRR - 08PP - TTSSRR - 12PP TTSSRR - 02PP - TTSSRR - 16PP - TTSSRR - 20PP TTSSRR - 24PP - TTSSRR - 30PP - TTSSRR - 40PP TTSSRR - 50PP - TTSSRR - 60PP - TTSSRR - 80PP TTSSRR - 10PP - TTSSRR - 12 - TTSSRR - 14 - TTSSRR 18 - TTSSRR - VtVtVvVv - $\mathrm{K}_{\mathrm{E}} \mathrm{K}_{\mathrm{E}} \mathrm{K}_{\mathrm{E}} \mathrm{K}_{\mathrm{N}} \mathrm{K}_{\mathrm{N}} \mathrm{K}_{\mathrm{N}}$.

METEO - Meteorological report;

11 - indication of Meteorological report METEOSTŘEDNÍ;

ČC̆ - No. of meteorological unit that purchased the report;

DD - day of the end of sounding (without giving a month);

$\mathrm{HH} \quad-$ hour of the end of sounding;

$\mathrm{M} \quad$ - tens of minutes of the end of sounding;

VVVV - altitude of posts of artillery weather unit (AWU) 
in meters (rounded to meters);

$\mathrm{BBB}$ - change ground pressure due to the table value at an altitude of meteorological unit;

To To - change the virtual ground air temperature due to the table in ${ }^{\circ} \mathrm{C}$;

hh - codes of standard heights, the standard height of 8000 are hektometers, above in kilometers;

PP - medium change in air density due to the table value;

TT - medium change in virtual temperature of air due to the table value;

SS - bearing of medium wind (where the wind blows) in hundreds of mils;

RR - speed of medium wind in meters per second;

$\mathrm{VtVt}$ - reached altitude of temperature sounding in kilometers;

$\mathrm{VvVv}_{\mathrm{V}}$ - achieved high of wind sounding in kilometers;

$\mathrm{K}_{\mathrm{E}} \mathrm{K}_{\mathrm{E}} \mathrm{K}_{\mathrm{E}}$ - horizontal coordinates of the meteorological station unit according to coded map 1:100 000;

$\mathrm{K}_{\mathrm{N}} \mathrm{K}_{\mathrm{N}} \mathrm{K}_{\mathrm{N}}$ - vertical coordinates of the meteorological station unit according to the same map.

\section{B. Using report}

Data from the reports required for the calculation of the corrections calculated elements for fire $\left(\Delta \mathrm{D}_{\mathrm{U} P}, \Delta \mathrm{S}_{\mathrm{U}} \mathrm{P}\right)$ shall be adjusted and applied as follows:

- Based on the number of meteorological unit that compiled the report and its position (as coded maps $1: 100000)$, it is possible to determine the spatial validity of meteorological report.

- Use information about the day, hour and tens of minutes of the end of sounding and position of the meteorological sounding unit can determine the duration of the report.

- Altitude of meteorological station unit is used to calculate altitude meteorological stations due to fire position and the change of ground pressure due to the table value at an altitude of meteorological unit conversion change ground pressure for altitude of firing position.

- Changing the virtual ground air temperature due to the table for the calculation of the corrections calculated element does not use.

- The codes of standard heights correspond to the drop ceiling atmosphere above the weather station. Ballistic values of the required characteristics of the atmosphere, the standard for the height values are fictitious, and generally affect shots flight the same way as the actual conditions during shots flight which changes. When calculating the correction of calculated elements is counted with those characteristics of the atmosphere, which are listed in the layer, the ceiling is the closest relative height above the top of the missile flight path corresponding to the topographic distance of firing, and the type shots and lighter filling, you will be firing.

- Medium change in air density due to the table value for the calculation of the corrections calculated elements does not use.

- Medium change in virtual air temperature due to the table value, bearing medium wind speed and wind in the corresponding middle layer is used to determine the overall influence of meteorological conditions on the flight of missiles firing.

- Achieved high temperature and wind soundings to calculate corrections calculated elements does not use.

\section{MeteOrologiCAL REPORT METEOSTŘEDNÍ- PŘIBLIŽNÁ}

Meteorological report METEOSTŘEDNÍ-PŘIBLIŽNÁ is used to prepare elements for the firing as a substitute METEOSTŘEDNÍ meteorological report, if this is not available. The validity of this meteorological report in constant weather is 1 hour and only for the battalion with the Meteorological Unit report that compiled the report and is valid for heights of the weather reports to $800 \mathrm{~m}$ with a full preparation for firing elements.

\section{A. The importance of character message}

Scheme of report:

METEO-11 00 - DDHHM - VVVV - BBBToTo - 02 TTSSRR - 04 - TTSSRR - 08 - TTSSRR - 12 - TTSSRR - 02 TTSSRR - 16 - TTSSRR - 20 - TTSSRR - 24 - TTSSRR - 30 TTSSRR - 40 - TTSSRR

METEO - Meteorological report;

11 - Meteorological Report METEOSTŘEDNÍ designation;

$00 \quad-$ is replaced by the number of meteorological unit that compiled the report;

DD - day of the end of sounding (without giving a month);

$\mathrm{HH} \quad-$ hour of the end of sounding;

$\mathrm{M} \quad$ - tens of minutes of the end of sounding;

VVVV - altitude of posts of artillery weather unit (AWU) in meters (rounded to meters);

BBB - change ground pressure due to the table value at an altitude of meteorological unit;

To To - change the virtual ground air temperature due to the table in ${ }^{\circ} \mathrm{C}$;

hh - codes of standard heights, the standard height of 8000 are hektometers, above in kilometers;

TT - medium change in virtual temperature of air due to the table value;

SS - bearing of medium wind (where the wind blows) in hundreds of mils;

RR - speed of medium wind in meters per second. 


\section{B. Using report}

Data from the reports required for the calculation of the corrections calculated elements for fire $\left(\Delta \mathrm{D}_{\text {ÚP }}, \Delta \mathrm{S}_{\mathrm{U} \text { P }}\right)$ shall be adjusted and applied as follows:

- Use information about the day, hour and tens of minutes, and termination of sounding information, it is the meteorological report of the unit of the battalion; it is possible to determine the duration of the report. Jurisdiction meteorological unit is given to the section of broadcast meteorological reports in the network connecting of battalion.

- Altitude of meteorological station unit is used to calculate altitude meteorological stations due to fire position and the change of ground pressure due to the table value at an altitude of meteorological unit conversion change ground pressure for altitude of firing position.

- Changing the virtual ground air temperature due to the table for the calculation of the corrections calculated element does not use.

- The codes of standard heights correspond to the drop ceiling atmosphere above the weather station. Ballistic values of the required characteristics of the atmosphere, the standard for the height values are fictitious, and generally affect shots flight the same way as the actual conditions during shots flight which changes. When calculating the correction of calculated elements is counted with those characteristics of the atmosphere, which are listed in the layer, the ceiling is the closest relative height above the top of the missile flight path corresponding to the topographic distance of firing, and the type shots and lighter filling, you will be firing.

- Medium change in air density due to the table value for the calculation of the corrections calculated elements does not use.

- Medium change in virtual air temperature due to the table value, bearing medium wind speed and wind in the corresponding middle layer is used to determine the overall influence of meteorological conditions on the flight of missiles firing.

\section{Standard Ballistic Meteorological Message - METB}

Standard Ballistic Meteorological Message (METB) is used artillery armies that implemented STANAG 4061, in preparation for firing elements of an alternative manner. The validity at steady weather is given in the third group of meteorological reports, which indicates the period of the beginning of the report and the duration of its validity.

\section{A. The importance of character message}

Scheme of report:

METBKQ LALALALOLOLO YYG0G0G0G hhhPPP ZZddFF TTTDDD

ZZddFF TTTDDD ... group on each line of the report is repeated.

GROUP

MET Weather Report

B Report type: Ballistic

K User meteorological report (for whom the message is))

$\mathrm{K}=2$ for anti-aircraft fire

$\mathrm{K}=3$ for field artillery firing

Q Code earth octant (Table 3)

GROUP 2

If $\mathrm{Q}=0$ up to 3 or $\mathrm{Q}=5$ to 8 , then goes on to state: $\mathrm{L}_{\mathrm{A}} \mathrm{L}_{\mathrm{A}} \mathrm{L}_{\mathrm{A}} \mathrm{L}_{\mathrm{O}} \mathrm{L}_{\mathrm{O}} \mathrm{L}_{\mathrm{O}}$

$\mathrm{L}_{\mathrm{A}} \mathrm{L}_{\mathrm{A}} \mathrm{L}_{\mathrm{A}} \quad$ Latitude of the center of the area in tens, units and tenths of a degree.

$\mathrm{L}_{\mathrm{O}} \mathrm{L}_{\mathrm{O}} \mathrm{L}_{\mathrm{O}}$ Longitude of center of the area in tens, units and tenths of a degree. For longitude 100 to $180^{\circ}$ inclusive hundred digit omitted (example: 135 means $13^{\circ} 30^{\prime}$ or $113^{\circ} 30^{\prime}$ east or west longitude in the field of action units).

If $\mathrm{Q}=9$ then goes on to state: $\mathrm{XXXXXX}$

XXXXXX The location of the center of the area, openly or in code (alphanumeric) using the reference coordinate system of NATO (as defined in STANAG 2211), that is six digit reference coordinates. This allows the center was specified more precisely than is possible using geographical coordinates (latitude and longitude). Alternatively, it can be used to refer to XXXXXX place names, either openly or in code.

GROUP 3

YY Day of the month in which the validity of the report begins.

$\mathrm{G}_{0} \mathrm{G}_{0} \mathrm{G}_{0}$ World Time (Greenwich Mean Time, GMT) early in the time interval of tens, units and tenths of hours, during which used a 24-hour interval from 000 to 239 .

$\mathrm{G}$ Duration of the report in hours 1 to 8 hours. The code number 9 indicates the duration of the report 12 hours.

\section{GROUP 4}

hhh The default height of the meteorological station (Meteorological Plane date, MDP) above mean sea level in tens of meters. The default height of the meteorological station is the level of the earth's surface, which is related to the height of ballistic layers and elements. For the needs 
of ground forces is usually the weather station MDP height above the mean sea level.

PPP Air pressure at the level of MDP, expressed as a percentage, rounded to the nearest $0,1 \%$ standard pressure. If the pressure is equal to or greater than the standard, the first digit is omitted.

\section{GROUP 5}

ZZ The line number in a message indicating the line (two consecutive groups). Contents of the line are for the track of fire from field artillery, which reaches a peak height of the layer above the MDP.

dd The direction from which the wind blows in the ballistic layer, measured clockwise from geographic north, expressed in thousands and hundreds of mils. Encoded from 01 to 64 . Code 00 means that TABLE I

STANDARD TEMPERATURE AND AIR DENSITY FOR THE STANDARD BALLISTIC METEOROLOGICAL MESSAGE

the wind speed is zero.

FF Ballistic wind speed for a given layer, expressed in tents and units of knots.

\section{GROUP 6}

TTT Ballistic temperature in tens, units and tenth of a percent. If the ballistic air temperature is equal to or higher than the standard, the first digit is omitted.

$\Delta \Delta \Delta \quad$ Ballistic air density in tens, units and tenths of a percent. If the ballistic air density is equal to or higher than the standard, the first digit is omitted.

\begin{tabular}{|c|c|c|c|c|c|}
\hline \multirow[b]{2}{*}{$\begin{array}{c}\text { line } \\
\text { Number(zz } \\
\text { ) }\end{array}$} & \multirow[b]{2}{*}{$\begin{array}{l}\text { Standard or target height } \\
\text { above the top of the track } \\
\text { weather stafions }\end{array}$} & \multirow{2}{*}{\multicolumn{2}{|c|}{$\begin{array}{l}\text { Standard height of the } \\
\text { layer (base (Z) - ceiling } \\
\text { (S)) of the weather stason }\end{array}$}} & \multicolumn{2}{|c|}{ The default value } \\
\hline & & & & \begin{tabular}{|c|} 
temperature \\
(K) \\
[ST]
\end{tabular} & $\begin{array}{c}\text { density } \\
\left(\mathrm{g} / \mathrm{m}^{3}\right) \\
{[\mathrm{SH}]}\end{array}$ \\
\hline 0 & 0 & výška met & tanice & 288,150 & 1225,0 \\
\hline 1 & 200 & 0 & 200 & 287,500 & 1213,3 \\
\hline 2 & 500 & 200 & 500 & 285,875 & 1184,4 \\
\hline 3 & 1000 & 500 & 1000 & 283,275 & 1139,2 \\
\hline 4 & 1500 & 1000 & 1500 & 280,025 & 1084,6 \\
\hline 5 & 2000 & 1500 & 2000 & 276,775 & 1032,0 \\
\hline 6 & 3000 & 2000 & 3000 & 271,900 & 956,86 \\
\hline 7 & 4000 & 3000 & 4000 & 265,400 & 863,23 \\
\hline 8 & 5000 & 4000 & 5000 & 258,900 & 776,77 \\
\hline 9 & 6000 & 5000 & 6000 & 252,400 & 697,11 \\
\hline 10 & 8000 & 6000 & 8000 & 242,650 & 589,50 \\
\hline 11 & 10000 & 8000 & 10000 & 229,650 & 466,35 \\
\hline 12 & 12000 & 10000 & 12000 & 218,275 & 363,39 \\
\hline 13 & 14000 & 12000 & 14000 & 216,650 & 265,48 \\
\hline 14 & 16000 & 14000 & 16000 & 216,650 & 193,67 \\
\hline 15 & 18000 & 16000 & 18000 & 216,650 & 141,29 \\
\hline 16 & 20000 & 18000 & 20000 & 216,650 & 103,07 \\
\hline 17 & 22000 & 20000 & 22000 & 217,650 & 74,874 \\
\hline 18 & 24000 & 22000 & 24000 & 219,650 & 54,280 \\
\hline 19 & 26000 & 24000 & 26000 & 221,650 & 39,466 \\
\hline 20 & 28000 & 26000 & 28000 & 223,536 & 28,777 \\
\hline 21 & 30000 & 28000 & 30000 & 225,518 & 21,042 \\
\hline
\end{tabular}

\section{B. Using report}

Data from the reports required for calculation of the corrections calculated elements for fire $\left(\Delta \mathrm{D}_{\mathrm{U} P}, \Delta \mathrm{S}_{\mathrm{UP}}\right)$ shall be adjusted and applied as follows:

- Carry out inspection of the type of report if the report is intended for field artillery fire and whether it is the right Earth octant.

- Evaluate if the firing unit is located in an area of meteorological report and if the report is valid in terms of time. Spatial validity of the standard ballistic meteorological report is not fixed, but given the similarity of content can be used for standard artillery computer meteorological report METCM, which is valid within $50 \mathrm{~km}$ from the meteorological unit station.

- The default height of the meteorological station, which is given in tens of meters, multiplies by the 10 . The result, altitude meteorological station in meters, is used to calculate altitude meteorological stations due to the gun position. Air pressure at the level of MDP as a percentage shall be converted to ground-level air pressure change due to the value in the table altitude of meteorological unit. Using the elevation values of meteorological stations and changes in ground level air pressure to calculate changes in air pressure for ground-altitude firing position.

- The line number indicates the row in the report, which defined for the base layer of the atmosphere and the ceiling, the base of the upper layer is identical to the cap layer that lies beneath. Values bases and ceilings of all layers are shown in Figure 2 default values of temperature and air density for the standard ballistic meteorological report. Ballistic values of the characteristics of the atmosphere, specified for the layer are fictitious values in the layer affect flight of missile the same way as the actual conditions during missile flight changes. When calculating the correction elements must be calculated to determine layer, the ceiling is the closest relative height above the top of the missile flight path corresponding to the topographic distance firing, projectiles and lighter type and content, which leads to firing. The required characteristics of the atmosphere are obtained by the sum of the values measured characteristics for the top layer and all lower layers. The weighting values of the measured values of the characteristics of the atmosphere multiplied are shown in Table 2.

- Ballistic wind direction is calculated by adding multiples of weight values and bearing ballistic wind measured in all layers from the level of meteorological stations for the layer containing the relative peak missile flight path. For needs of artillery of the Army of the Czech Republic, the resulting value multiplied by the constant 0,9375 which are converted mils to Czech angular 
rate - mils.

- In the same way as the wind direction is calculated ballistic wind speed with the only difference being that the resulting amount is multiplied by a constant 0,5156 by which are knots converted to meters per second.

- Ballistic air temperature in percentages will be recalculated as follows:

oballistic air temperature recorded in each layer is divided by 100 and multiplied by the standard temperature in degrees Kelvin for the layer that is shown in Figure 1;

ofrom the calculated value is deducted table value standard temperature in degrees Kelvin, which is for weapon systems introduced in the Czech Army 288,15 K now;

othis value is multiplied by the weight value of air temperature in the layer;

othe resulting values for the individual layers are added and thus to obtain the total change in ballistic air temperature to the desired height relative to the top of the missile flight path.

- The adjustment value direction and wind speed and air temperature are used to determine the overall influence of meteorological conditions on the flight of missiles firing.

- Ballistic air density to calculate the corrections calculated elements does not used.

Converting the values of reports METEOSTŘEDNÍ and TABLE II

DEFAULT VALUES OF TEMPERATURE AND AIR DENSITY FOR THE STANDARD BALLISTIC METEOROLOGICAL REPORT

METB, assembled under one and the same measurements, and converted to the same unit was found that the values differ, even if the height layers are identical. Based on consultations with the authorities of weather service of the Czech Army, utilizing the same means of ascertaining the meteorological conditions such as artillery, it was found that a simple conversion is not possible because of the use of a completely different algorithm composing the report, and use of unknown coefficients. It follows that the report METB does not describe exactly the firing conditions, which are used in calculating the elements of a complete preparation for firing of artillery in terms of Czech Army. Until the identification of differences in reports do not recommend METB to calculate the fire elements.

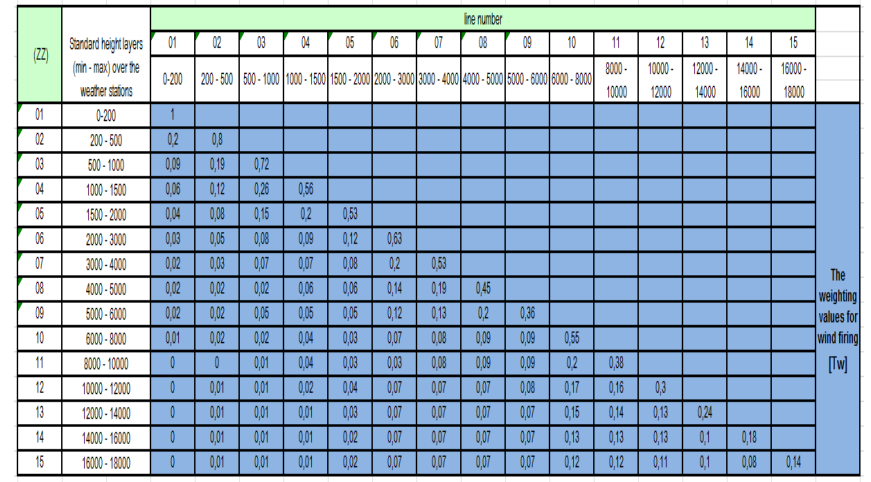

\section{V.STANDARD ARTILLERY COMPUTER METEOROLOGICAL REPORT - METCM}

Standard Artillery Computer Meteorological Report (METCM) is used by artillery armies that implemented STANAG 4082, in preparation for firing using the computer components. The validity of report in steady weather is given in the third group of meteorological reports, which indicates the period of the beginning of the report and the duration of its validity. Spatial validity is $50 \mathrm{~km}$ from the meteorological station.

\section{A. The importance of character message}

Scheme of report:

METCMQ $\quad \mathrm{L}_{\mathrm{A}} \mathrm{L}_{\mathrm{A}} \mathrm{L}_{\mathrm{A}} \mathrm{L}_{\mathrm{O}} \mathrm{L}_{\mathrm{O}} \mathrm{L}_{\mathrm{O}} \quad \mathrm{YYG}_{0} \mathrm{G}_{0} \mathrm{G}_{0} \mathrm{G}_{0} \quad$ hhhPdPdPd ZZddFF TTTTPPPP

ZZddFF TTTTPPPP ... group on each line of the report is repeated.

\section{GROUP 1}

MET Weather report

CM The report type: computer

Q Code earth octant (table 3)

\section{GROUP 2}

If $\mathrm{Q}=0$ to 3 or $\mathrm{Q}=5$ to 8 , then goes on to state: $\mathrm{L}_{\mathrm{A}} \mathrm{L}_{\mathrm{A}} \mathrm{L}_{\mathrm{A}} \mathrm{L}_{\mathrm{O}} \mathrm{L}_{\mathrm{O}} \mathrm{L}_{\mathrm{O}}$

$\mathrm{L}_{\mathrm{A}} \mathrm{L}_{\mathrm{A}} \mathrm{L}_{\mathrm{A}} \quad$ Latitude of the center of the area in tens, units and tenths of a degree.

$\mathrm{L}_{\mathrm{O}} \mathrm{L}_{\mathrm{O}} \mathrm{L}_{\mathrm{O}}$ Longitude of center of the area in tens, units and tenths of a degree. For longitude 100 to $180^{\circ}$ inclusive hundred digit omitted (example: 135 means $13^{\circ} 30^{\prime}$ or $113^{\circ} 30^{\prime}$ east or west longitude in the field of action units).

If $\mathrm{Q}=9$ then goes on to state: $\mathrm{XXXXXX}$

XXXXXX The location of the center of the area, openly or in code (alphanumeric) using the reference coordinate system of NATO (as defined 
in STANAG 2211), that is six digit reference coordinates. This allows the center was specified more precisely than is possible using geographical coordinates (latitude and

\begin{tabular}{|c|c|c|}
\hline Q-code & $\begin{array}{l}\text { Longitude from } \\
\text { Greenwich }\end{array}$ & hemisphere \\
\hline 0 & 0o until 90o W & \multirow[t]{4}{*}{ northern } \\
\hline 1 & 90o until 180o W & \\
\hline 2 & 180o until 90o E & \\
\hline 3 & 90o until 0o E & \\
\hline 5 & 0o until 90o W & \multirow[t]{4}{*}{ southern } \\
\hline 6 & 90o until 180o W & \\
\hline 7 & 180o until 90o E & \\
\hline 8 & 90 o until 0o E & \\
\hline 9 & \multicolumn{2}{|c|}{$\begin{array}{l}\text { This code applies where the center of the } \\
\text { report does not defined by the geographical } \\
\text { latitude and longitude. }\end{array}$} \\
\hline
\end{tabular}

longitude). Alternatively, it can be used to refer to XXXXXX place names, either openly or in code.

\section{GROUP 3}

YY Day of the month in which the validity of the report begins.

$\mathrm{G}_{0} \mathrm{G}_{0} \mathrm{G}_{0}$ Greenwich Mean Time, (GMT) of the report begins in the time interval of tens, units and tenths of hours, which used a 24-hour interval from 000 to 239 .

G Duration of the report in hours 1 to 8 hours. The code number 9 indicates the duration

\section{GROUP 4} of the report 12 hours

hhh Height of MDP, where the weather station is located above the mean sea level in tens of meters. The default height of the meteorological station is the level of the earth's surface, which is related to the height of ballistic layers and elements. For the needs of ground

TABLE III

CODES FOR COUNTRY OCTANT

forces is usually the weather station MDP height above the mean sea level.

PdPdPd Air pressure at the level of MDP expressed in hundreds, tens and units of millibars. If the air pressure over 1000 millibars thousand digits are omitted.

\section{GROUP 5}

ZZ The line number in the report indicating the line (two consecutive groups). Contents of the line are for the track of fire from field artillery, which reaches a peak height of the layer above the MDP.

ddd The direction from which the vector of mean wind is directed, in measured clockwise from geographic north, expressed in thousands, hundreds and tens of mils. Encoding from 001 to 640. Code 000 means that the wind speed is zero. The value for the zero zone is the wind direction measured at the level of MDP.

FFF Mean wind speed for the zone in terms of hundreds, tens and units of knots. The value for the zero zone is the wind speed measured at the level of MDP.

\section{GROUP 6}

TTTT Mean virtual temperature zone in hundreds, tens, units and tenths of a degree Kelvin. The value for the zero zone 00 represents the temperature at MDP.

PPPP Air pressure in the middle altitude zone, expressed in thousands, hundreds, tens and units of millibars. The value for zero pressure zone is measured at the level of MDP.

\section{B. Using report}

Data from the reports required for calculation of the corrections calculated elements $\left(\Delta D_{U}, \Delta S_{U}{ }_{U}\right)$ are processed automatically and artillery authorities have no possibility to influence the calculations numbered elements. For the artillery forces of NATO member states is developed softwareSG/2 Sharable Software Suite (S4), which includes a module NATO Armaments Meteorological Kernel (NAMK). Module NAMK processes meteorological data for further use within the software S4. In addition, one of the functions of the module NAMK is forecasting weather conditions. This reduces one of the biggest mistakes that results from meteorological preparing, and the difference between measured and actual weather conditions, allowing for more accurate artillery fire on the distance over $30 \mathrm{~km}$.

Artillery of Czech Republic uses data from the METCM report for calculating the adjustments corrections calculated elements for fire control in a similar method using the automated fire control system called ASPRO (Automated Artillery Fire Support Control System).

\section{CONCLUSION}

Artillery of Czech Republic currently has to eliminate errors caused by meteorological influences four types of meteorological reports. Three of them are destined for manual processing and one for computer processing. Report METB cannot be used to calculate the fire element for complete preparation in terms of the Czech Army artillery.

All kinds of the report can be used to calculate the complete preparation for firing, the weather report METEOSTŘEDNÍPŘIBLIŽNÁ but only with those restrictions.

When using NATO S4 is possible for the automatic processing of meteorological data used METCM report without any further software development. Simultaneously is guaranteed compatibility with other sources of meteorological 
data in the framework of NATO.

It is necessary to precisely define the reporting procedures, with emphasis on the METB report and possibly METCM report, and prepare the report METB conversion algorithm (METCM) on METEOSTŘEDNÍ and possibly revise the manual calculation of the complete preparation using the report METB (METCM).

\section{REFERENCES}

[1] Military Strategy of The Czech Republic. Praha: MO CR, 2008.

[2] Long-Time Scheme of Ministry of Defence. Praha: MO CR, 2008.

[3] NATO Capabilities/Statements - 2018. Brusel, 2007.

[4] Doctrine of the Army of the Czech Republic. Praha: MO CR, 2005.

[5] BLAHA, M., SOBARŇA, M. Some develop aspects of perspective Fire Support Control System in Czech Army conditions. In The $6^{\text {th }}$ WSEAS International Conference on Dynamical Systems and Control. Sousse (Tunisia): University of Sfax, 2010, pp. 179 - 183.

[6] BLAHA, M., SOBARŇA, M. Principles of the Army of the Czech Republic Reconnaissance and Fire Units Combat using. In The $15^{\text {th }}$ International Conference ,, The Knowledge-Based Organization“. Sibiu (Romania): Nicolae Balcescu Land Forces Academy, 2009, pp. 17-25.

[7] POTUŽÁK, L. Control and Realization of Fire Support - The Cooperation of Artillery and Units of Artillery Reconnaissance during Fire Support of Forces. Partial task - Specific research of FEM. Brno: University of Defence, 2006.

[8] AD-6.1 Doctrine of Communication and Information systems. Praha: MO CR, 2003.

[9] AAP-6 NATO Glossary of Terms and Definitions (english and french). 2009.

[10] BLAHA, M., BRABCOVÁ, K. Decision-Making by Effective C2I system. In The $7^{\text {th }}$ International Conference on Information Warfare and Security. Seattle (USA): Academic Publishing Limited, 2012, pp. 44-51. ISBN 978-1-908272-29-4

[11] BLAHA, M., BRABCOVÁ, K. Communication environment in the perspective Automated Artillery Fire Support Control System. In The 10th WSEAS International Conference on APPLIED INFORMATICS AND COMMUNICATIONS (AIC '10). Taipei, 2010. pp. 236-240. ISBN 978-960-474-216-5.

[12] BLAHA, Martin. Communication as a basic for future Artillery Fire Support Control System. In: The European Conference of COMMUNICATIONS (ECCOM'10). Tenerife: WSEAS Press, 2010, p. 140-142. ISBN 978-960-474-250-9.

[13] BLAHA, Martin; POTUŽÁK, Ladislav. Decisions in the perspective Automated Artillery Fire Support. In: Recent Researches in Applied Informatics \& Remote Sensing. Penang: Wseas Press, 2011, p. 87-91. ISBN 978-1-61804-039-8.

[14] PIKNER, Ivo; GALATIK, Vlastimil. FUTURE OPERATIONAL ENVIRONMENT AND MILITARY CONCEPTS. In: $16 T H$ INTERNATIONAL CONFERENCE THE KNOWLEDGE-BASED ORGANIZATION: MANAGEMENT AND MILITARY SCIENCES. Sibiu, ROMANIA, 2010, p. 157-161. ISSN: 1843-6722.

\section{Creative Commons Attribution License 4.0 (Attribution 4.0 International, CC BY 4.0)}

This article is published under the terms of the Creative Commons Attribution License 4.0 https://creativecommons.org/licenses/by/4.0/deed.en_US 